Peer review: This article has been subject to a double-blind peer review process

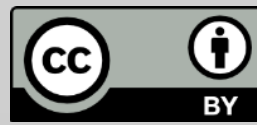

Copyright notice: This article is issued under the terms of the Creative Commons Attribution License, which permits use and redistribution of the work provided that the original author and source are credited.

You must give appropriate credit (author attribution), provide a link to the license, and indicate if changes were made. You may do so in any reasonable manner, but not in any way that suggests the licensor endorses you or your use. You may not apply legal terms or technological measures that legally restrict others from doing anything the license permits.

https://creativecommons .org/licenses/by/4.0/

\section{Geosocialities, Flow and Renewal in Microbial Rivers}

\author{
Serena Zanzu \\ Warwick Business School, University of Warwick, UK \\ Correspondence: s.zanzu@warwick.ac.uk \\ ORCID: 0000-0002-8925-9224
}

\begin{abstract}
This article draws on interview data and insights from environmental studies and somatic therapy to argue for the significance of thinking 'with rivers' in order to reaffirm human and nonhuman entanglements in the current challenges presented by anthropogenic devastation. River microbial communities are unintelligible and complex entities due to their unclear origin and continuous flow downstream. The account of one environmental scientist is presented to consider how the metaphors of movement used in the riverine context assist in exploring the complicated dynamics of fluid communities facing constantly changing environments I call 'microbial rivers'. A pollution incident affecting a UK river, where microbial communities responded by growing in number and activity, further illustrates the intersection of communities and ecosystems in their adaptation to troubling human interventions. Engaging with somatic understandings of trauma, this article proposes thinking with flow as a possibility to reimagine the capacity for renewal when experiencing debilitating adversities, thus countering apocalyptic responses of immobility in the face of environmental destruction and inviting novel opportunities for growth for human and nonhuman communities.
\end{abstract}

Keywords: water; river; microbial communities; geosocialities; flow 


\section{Water Imaginations}

The existence of life is profoundly interconnected with the water element; all life on earth relies on water for its survival (Harding \& Margulis, 2010; Hawke, 2012). However, water is currently undergoing a crisis driven by pollution, lack of access and unsustainable farming practices. In western societies characterised by a focus on production and the exploitation of resources, water emerges as a mere commodity (Hawke, 2012). This article proposes a reawakening of water as a vital and finite element in need of attention, admiration and reverence. Drawing on recent calls 'to bring water forward for conscious and careful consideration' (Chen et al., 2013: 3), I argue that thinking with water entails the acknowledgement of this fluid element as more than an essential resource. If water is a powerful force behind all activities that needs to emerge from invisibility, this 'aqueous ecopolitics' (Ibid: 6) not only involves all life forms but also crosses over temporal trajectories involving previous, present and future lives in the consideration of water. It is a politics that requires situating water but also situating humans, typically land organisms, within challenging liquid settings. In acknowledging the somatic significance of water, and rivers in particular, for human and nonhuman bodies such as plants, it is possible to notice the diverse ways in which water is politically and geographically located in its continuous dynamic and transformative potential (Chen et al., 2013).

Water holds a 'configurative power' that shapes social life and values in fundamental ways (Hastrup, 2013: 59). Moving beyond an understanding of society as land-based and immobile, water allows for apprehending social life as moving and fluid. Through their bends and twists, rivers undergo a transformation from natural elements to human industrial resources, with tensions between demands unequally affecting river populations along different sections of the river flow upstream and downstream. Touching cities and communities, rivers are transformed and in turn transform social life itself (Hlbid). The social and political dimensions of water emerge as a 'hydrosocial cycle', a concept that emphasises the dynamic relations and reciprocal co-creation between water and society, thus addressing 'the agential role played by water' (Linton \& Budds, 2013: 170). In this perspective, water and society are interrelated realms involved in situated and coproduced relations with political and vested interests, where water is constituted as a public good but also as a commodity. In the recognition of these interrelations, there have been calls for a consideration of water beyond its biological qualities that acknowledges the many layers in which this element intersects with social and political life and with public health (Orlove \& Caton, 2010). Because of its materiality and value as both a resource and a right, water is positioned within questions of justice, equity of access, distribution and 
sustainability (Ibid). Acknowledging the interrelation of organisms also requires new ways to think about ethics and social justice beyond a mere resource-based approach (Yaka, 2020). If humans' identity and ways of knowing the world are formed through the encounter with other nonhuman bodies, river waters and anti-hydropower movements can be considered from an environmental justice perspective aimed at reconciling human and nonhuman justice (Ibid).

While I draw on these debates, my main theoretical proposal is aligned with the possibility for human-water relationships that go beyond exploitative and anthropocentric approaches to watercourses and their visible and invisible communities. This entails, as suggested by Myra Hird, taking the microbial world seriously (2009). To engage meaningfully with water and its inhabitants, I propose the concept 'microbial rivers', watercourses that are affected by, and in turn influence, human and nonhuman communities, as a way to think about the interconnected relationships between potentially destructive practices and flowing river populations, visible and invisible. I, therefore, join Hird's proposition of an ethics of the microbial for social scientists that overcomes anthropocentric assumptions. Building on Donna Haraway's invitation for species-meeting entanglements, Hird goes beyond companion species to encounter relationalities with different domains. This is because bacteria are typically excluded from social scientists' considerations of entanglements. For Hird, this microbial ethics 'must begin with an appreciation of these minute creatures' beyond harmful characterisations (Ibid: 142). With analogous aims, exploring marine microbes, Astrid Schrader proposes to overcome anthropocentrism, stating: 'marine microbes disrupt the individual/population dichotomy and the opposition between life and death that have been central to an anthropocentric notion of biopolitics' (Schrader, 2020: 259). In particular, Schrader offers an invitation to decentre the human through thinking with, and about, marine microbes' death (Schrader, 2017).

I consider these propositions particularly useful in exploring the entanglements with river microbes and other fluvial communities as a way to advance a decentring of the human that allows for more attentive and respectful relations with other life forms. For this purpose, I adopt the notion of geosocialities as the entangled relations of the earth and biologic beings', to think about the materiality of the earth in which humans and nonhumans live (Pálsson \& Swanson, 2016: 150). Geosocialities embrace the expansion of the 'social' that now increasingly includes more than human relations and in particular poses attention to the mineral side of the story that has so far struggled to be considered. Stones and rocks have not been included in what social scientists consider social life. Geosocialities show how biological bodies contain geological 
ones. If geosocialities aside rocks include water, as 'the term cannot be simply read as geos = rocks and social = people' (Ibid: 160), in this article I propose that rivers, in particular, are never only about water but are entangled with pollutants, sediments and soils as well as the communities they convey. Rivers are then geosocial entities inextricably consociated with humans and other bodies such as oceans, soil and air. This meeting of geological and social realities entails a reconsideration of rivers as worthy interlocutors and therefore suggests novel and horizontal 'hydrologics' relationships that are able to decentre the human (Hawke \& Pálsson, 2017: 236). And while for Gisli Pálsson and Heather Swanson (2016) geosocialities assist precisely in addressing those minerals that unlike microbes have not been included in nonhuman biosocial explorations, I argue that river microbes are deeply involved in geosocial relations with other species as well as anthropogenic toxic substances such as pesticides. This is because they are entangled with ground source materials and with the unceasing moving environment in which they live their lives. It is in considering these relationships and moving away from Descartes' dualism characterising natural elements as passive and culture as active, that rivers can regain agency and significance (Hawke \& Pálsson, 2017). These new relations include conscientiousness, sustainability and appreciation for the specific nonhuman that is the river. Rivers and other bodies of waters can then be considered beyond the ecosystem services they provide and come to matter as crucial resources entangled with all living beings of the earth. This shift, involving the appreciation and understanding of rivers, also entails the awakening of 'nature consciousness' where the river is no longer a natural capital to exploit but an entity that contains agency and symbolic meaning (Ibid: 237).

'Thinking relationships through water' has been suggested as a way to move the attention away from a conception of water as a mere resource or object over which humans construct particular meanings, and to instead regard water in its 'generative and agentive' relationalities (Krause \& Strang, 2016: 633). Thinking through water allows then to include other actors in the complex layers of social interconnections. Because water is shared across multiple nonhumans such as plants and other animals, it is well-positioned to provide insights into human-nonhuman relationships (Krause \& Strang, 2016). It is in this sense that flowing, geosocial rivers can assist in contributing to the growing project advanced in the humanities and social sciences to decentre the human from its protagonist role in the story of life. This shift can, in turn, allow for the establishment of novel relationships with nonhuman rivers, microbial communities and other life forms, necessary to tackle the current anthropogenic destruction affecting human and nonhuman populations. 
Employing the metaphor of flow here is useful in 'tracing the simultaneously social and material exchanges through which the world comes into being' (Krause, 2014: 91). River ecosystems, as well as human flow in wellbeing, share a need to be 'unstuck' from the constriction of trauma and the violence of poisonous substances that disintegrate communities. A flowing river, a flowing human experience, illustrate the complex ways in which environmental and psychological devastation can freeze and constrain entire communities, where individual resilience is not always what matters. Instead, it is through multispecies communities-of rivers, microbes, crustaceans, humans - that strength and renewal can emerge.

Metaphors 'silently direct our thought patterns and actions' and analogies of flow are currently pervading the social sciences, to indicate a 'natural' circulation of capital, people and ideas (Féaux de la Croix, 2011: 488). 'Flow' has become the most relevant metaphor employed to conceptualise globalisation and the large-scale mobility of time, goods, people and money, but also processes and relations (Rockefeller, 2011). The use of the word can be at times implicit and unaware, thus establishing assumptions and dualisms that are not scrutinised. Stuart Alexander Rockefeller argues that in many of these uses, there is nothing naturally or smoothly flowing. Employing a watery comparison, he states that "global flows" are not, like the water of a river, the objective result of uniform substances responding to uniform conditions.' (Rockefeller, 2011: 567). Despite this seemingly deterministic description of rivers as uniform, Rockefeller acknowledges that even watercourses do not flow in uniform and naturalised conditions.

Drawing on these considerations, I acknowledge the contextuality of flow, and of the blockage that follows the building of a river dam or an overwhelming experience. There is no single, homogeneous flow, in a river or in human wellbeing. As rivers follow their course, they reach larger plains with slower and almost negligible movement. They then become more rapid as they reach steeper segments. Slopes and altitude affect their movement, as do rocks and precipitations. Aligning with this contextuality of flows and rivers, in the following section I propose a singular perspective from an environmental scientist and then elaborate on how a polluting incident, occurred in a specific river, had particular ecosystem implications for resilience and destruction that raise the question: how to engage with rivers in conscientious modalities and how does the river speak? 


\section{Emerging Microbial Rivers}

In order to explore the forms that a new conversation with rivers can take, I engage with the field of microbiology that studies the microbial communities living in diverse environments such as the human gut, soils and oceans. The microbiome of river settings is only beginning to receive more attention in environmental studies of watercourses. Rivers are considered crucial for the ecosystem services they supply such as hydropower, irrigation and the provision of drinking water (Savio et al., 2015). The importance of rivers in carbon cycling is linked to the rising concerns that rivers transport and pour carbon into the sea. In this perspective, rivers become paths to somewhere else-the ocean-and carry with them carbon and precious soil from degraded arable land that travels to rivers and goes out to sea, resulting in soil loss. Freshwater ecosystems, therefore, are considered 'as conduits between terrestrial and marine environments' (Clark et al., 2018: 2). Increasing evidence also address important questions around the interconnection between the human gut microbiome and rivers, considered both in terms of the human influence on rivers through wastewater, and of the bacterial presence in drinking water that is believed to influence the human microbiome (VazMoreira et al., 2014). This 'link between water habitats and the human body' raises health-related issues such as antibiotic resistance (Ibid: 770). According to these characterisations, humans contain microbes that end up in wastewater; watercourses contain microbes that end up in humans. Microbial rivers emerge, therefore, as interconnected entities where the invisible component comes to matter for its capacity to affect and influence multiple geosocialities and ecosystems.

To explore how the microbial communities of rivers are currently constituted in the scientific domain, I propose the case study of a bioinformatician and environmental scientist I interviewed in 2018 as part of my research on the soil microbiome. Based at a UK university, Jules studies the microbial communities living in environments, from the human gut to soil and rivers. Aside from considering rivers as a source of drinking water and for their role in the carbon cycle, he also underlines the 'social impact' related to a 'romantic' relationship that connects humans and rivers. For Jules, the 'river as a whole is unique' and it 'makes people always curious about rivers ... always wanting to relate with the river in some way or another'. This description seems to point to the 'imaginative implications' of water, an element pervaded with meaning, sensorial experience and perception (Hastrup, 2013: 60). Water holds rhythmic, magnetic and mesmerising qualities for the visual and hearing sense that are conducive to altered states of consciousness (Strang, 2004). The senses of taste, smell and touch are also important in affective water relationships, with experiences of immersion referring back to a prenatal 
memory. Water holds an aspect of essentiality for all life itself and the river, in particular, conveys the meaning of a living entity and the passage of time (Ibid).

When Jules regards rivers in their scientific as well as their 'social' significance, he seems therefore aware of some of the implications of his work for the wider society, as he deems the relationship with rivers an ingrained feature of human life. In this way, he seems to counter a purely anthropocentric approach focused on ecosystem services. When discussing the importance of rivers, Jules only employs the importance of watercourses in the provision of services to justify the relevance of his work. In this sense, he finds himself under the obligation to legitimise his scientific research for funding and impact requirements, as shown in the following quote:

With limited funding, you really have to make your story sound ... like an important science. I don't believe one science is more important than another but certainly, you really have to sell your story in the best way you can. (Author's interview with Jules, 2018)

Thus, the mere services rivers provide do not constitute Jules' main drive. The deeper reason motivating his research on river microbial communities lays in an interest for a still unknown field within microbiome studies. When explaining the relevance of rivers, rather than merely connecting his research to human needs and benefits, he claims to be motivated by curiosity: 'I do science because I'm curious ... obviously, we are responsible scientists, we want to be responsible but predominantly, well, primarily we do science because we are curious about what's happening in a river.' Jules' willingness to be a responsible scientist therefore inevitably clashes with the main drive for his work, which emerges as interest and 'curiosity'. While Jules' curiosity seems to counter a view focused on rivers as a capital to exploit, curiosity in this context is not necessarily unproblematic. When scientists emphasise the excitement of discovery as their motivation for doing science, they reaffirm the idea of science as an innocent and natural endeavour born merely out of a drive to know (Sarukkai, 2009). Scientific curiosity in this sense also entails the idea of freedom and possibly of lack of responsibility. Curiosity may end up driving environmental damage for the sake of knowledge (Ibid). It is possible to say that Jules is aware of an ambiguity in recognising the scientific and social relevance of rivers and at the same time claiming to be driven by curiosity while declaring a commitment to responsibility.

In recent years, Jules has collected over a hundred samples at ten different points along the river Thames, southern England, from upstream down to wider sections of the river. He has carried out most of the tasks by himself, designing the experiment from beginning to end, setting a hypothesis, 
sampling, extracting DNA, sequencing and analysing the data. In what is known as a limnology study, he has compared microbial communities in the water, in the sediment and on biofilm in the rock, testing these three compartments 'as the river flows'. Jules' aim is to explore unanswered questions around the formation and composition of microbial communities:

Essentially I want to know how these microbes form a community in the water and in sediment ... we don't yet understand what processes are involved in those community assemblages, are they just flowing from roads, from farms, how do they form? Is there a stable community in the river? It looks like there are stable communities in the river but it's quite an interesting place to study because it's a one-way direction, it's always flowing, so are we seeing all the microbes from soil or are we seeing communities that are typical of the fresh water? ... Are there genuine fresh water sediment communities or do they look more like soil communities from farms for example? (Author's interview with Jules, 2018)

The particularity of any riverine ecosystem lays in its unidirectional flow that makes the study of its organisms' persistence significant (Mari et al., 2014). There is no agreement among researchers over the distinctness, variability and diversity of river microbial communities (Savio et al., 2015). Jules is therefore exploring whether there are 'genuine freshwater communities' or whether they are 'washed' from other sites. This is for Jules an important ecological question around the 'differences in the processes which allow the community to form' in rivers. Where do river communities come from and how do they form? What constitutes a stable community? These questions are currently largely unanswered due to the complexity of the river that emerges as an unintelligible object of study.

The river is quite a complicated place, because it's always flowing, so many, um, variables ... if there's a road above your sampling point you would have quite different potential communities, if there's a sewage outlet that would have another massive influence, if there is a farm, reservoir, ground water, all sorts of things can affect the river communities so much, it's actually quite difficult to figure out what's going on in a river. (Author's interview with Jules, 2018)

The emerging importance of microbes in the study of rivers is thus entangled with the attempt to understand the elusive origin, formation and composition of these communities in their geosocial interrelation with soil, rain and human interventions such as roads and farms. 
In this sense, watercourses are being constituted around the invisible communities of microorganisms they contain and that contain them. This is in line with a recent shift that occurred in the biological sciences. In the past two decades, microbes have emerged as important life forms across a range of environments and ecosystems in understanding, dealing with and providing solutions for anthropogenic destruction (Paxson \& Helmreich, 2014). This 'microbial turn' or 'microbial moment' entails a view of microbes that goes beyond mere determinism and instead constitutes microbes as dynamic and fluid forces (Ibid: 166). Heather Paxson and Stefan Helmreich argue that microbes are now seen as promising entities rather than solely harmful organisms. Microbes become signifiers of potentials and models that provide novel ways to read human relationalities with nature. These models are both descriptive and prescriptive, thus indicating the frame within which humans and microbes should relate (Paxson \& Helmreich, 2014). In marine microbiology, for instance, microorganisms living in the sea are currently portrayed as central figures responsible for fundamental biogeochemical processes (Helmreich, 2009). Emphasising the emergence of 'microbial seas' defined by the presence and significance of marine microbes, Helmreich points to a renewed understanding of oceans as well as of life itself, where 'life is being redistributed into a fluid set of relations' (Ibid: 8). Illustrating how viruses belong to our metagenome, Celia Lowe also emphasises the emergence of microbial life as a renewed lens through which to understand life, claiming that 'viruses are us' (2017: 94). In the current emergence of multispecies studies that emphasise the interconnection between organisms, because viruses emerge through their harmful potential, Lowe argues that viral studies configure themselves through an element of danger and infection (Lowe, 2017).

In line with these renewed characterisations of diverse environments now defined by microbial life, I extend the literature on microbial becomings to fluvial settings. Microbial rivers are places of uncertain origin, fluctuating composition and invisible lives. They come to matter in their interconnection with other elements such as sediment, reservoirs and sewage outlets; they are closely associated with the notion of movement and constant challenges. Microbial rivers also carry with them the rainfall that replenishes them, the oceans they are about to encounter and the soils they come from. It is indeed hypothesised, as noted by Jules, that river communities may originate from soil communities because 'abundant species in the downstream river are mostly found in soil water upstream'. These communities, however, are affected by a number of variables and Jules believes there is 'definitely a big difference' between river and soil communities. Ideas of movement and the changing nature of river courses emerge as particularly relevant in the understanding of these 
ecosystems. In describing the ways in which microbes are affected by rainfalls, Jules characterises them as being 'dragged down', conveying an image of microbial struggle. Rivers on the other hand are described as 'tricky' to study because of their variability.

People speculate that riverine communities are seeded by the soil communities ... some rivers are formed by ground fed, but you can imagine, it's washed, the rain falls hence washed and as it washes down the soil, the microbes, they get dragged down, they flow down, so it should resemble upstream. But as you can imagine all these microbes come to wide rivers, slow flowing wide rivers and there's lots of competition going on and so, it's quite complicated what survives, what doesn't and so it's, we don't quite understand quite what's going on in rivers ... there are so many different kinds of rivers ... and they all have quite a different characteristic, so that's what makes the river quite, quite tricky ... I would say more tricky than working with the ocean for example. Soil doesn't really move so much so that makes soil quite $a$, in a way, easier system to work with ... whereas in the river there are so many different factors ... it's complicated but really exciting. (Author's interview with Jules, 2018)

Because river microbes are sensitive to a number of variables including physical and chemical gradients, it is particularly complicated to build a coherent story around the origin of these communities. The changing and evolving nature of rivers at different sites means that the microbial communities are constituted as multifaceted and variable according to their location along the river course. Jules also believes that river communities are both deterministic and stochastic, thus both in competition with each other and randomly evolving depending on where they are situated. When he attempts to describe what goes on among river communities, Jules compares this environment to oceans and soils, claiming the superior complexity of rivers, in what seems a proud statement around convolution, also in line with the curiosity that drives his work. In this sense, for Jules the complexity of rivers, rather than discouraging scientific discovery, leads to excitement. The comparison with soil and, as I will show, with the human gut, illustrates how the microbiome becomes transferred metaphorically from one system to another. Soil ecosystems, human bodies and river communities then intersect to define and redefine each other through transpositions and metaphors. George Lakoff and Mark Johnson have observed how the entire system of human thought, action and experience is shaped by metaphors (1980). More than descriptive tools confined to the linguistic realm, metaphors invest conceptual systems and implicitly form our everyday life (Ibid). Veronica Strang also refers to homologues as images, models or frames of reference that are transposed from one system to the 
other (2004). The human body is one of the most frequent points of reference because of the shared physical experience of inhabiting a body (Ibid). In the following excerpt, Jules considers an analogy with the human gut, where he employs metaphors anchored to notions of fluidity and flow but also of competition, assistance and unceasing change. For Jules, the fluid nature of rivers, an element that makes them 'tricky' to study, can be seen in parallel with the flowing processes of human digestion and constant internal changes:

The river is a one-way flow so you start from the top and then you go down, as it goes down, in the river, lots of things happen ... something gets absorbed, something gets washed, some other inputs come in and as it travels down, the community changes ... and the same in the human gut ... lots of things happen and so communities change, communities compete, communities die and they, um, they form new communities, so it has that sort of parallel ... it's an ecology, in a gut you've got microbes forming communities, they are competing, they are helping. (Author's interview with Jules, 2018)

Jules' characterisation of gut microbes is in line with the sense of aliveness of the community proposed by Hird (2009) in her invitation toward 'thinking with microbes' in ways that overturn typical passive characterisations. These refashioninigs show instead the communicative, cooperative and intelligent nature of microbes. These ways of thinking can show, for instance, that gut bacteria are aware of human hormones, thus 'adjusting themselves accordingly' (Hird, 2009: 46). This 'gut sociality', a form of intercorporeal kind of relation between bodies within the human gut, is a way to think about the various organisms living in the gut, thus moving beyond an anthropocentric understanding of responsivity that now includes nonhumans (Neimanis, 2013). In his description of the formation and activities of communities and microbial actors, Jules seems to be aware of this form of sociality occurring within the human gut as well as watercourses.

As river communities encounter particular challenges related to their constantly changing environment, how do they react in the face of adverse events? What happens when microbial rivers are disrupted? To address these questions, I explore a pollution incident that occurred in 2013 when a spill of the toxic pesticide Chlorpyrifos affected the river Kennet, a tributary of the Thames (Thompson et al., 2015). The insecticide spill, first discovered by a citizen science group, revealed a resilient quality of the Kennet microbial communities. Macroinvertebrates such as crustaceans and insects were seriously affected and restructured by the spill. Their population decreased in numbers, with the 'collapse' of the freshwater crustacean Gammarus pulex (Ibid: 2044). Regarding microbial 
communities, however, 'there was no significant difference in the total abundance of bacteria' (Ibid: 2042). Microbial communities changed in composition and in carbon usage following the incident, but their population did not shrink. Instead, there was an increase in microbial activity and in their 'functional potential' as well as in the abundance of genes (Thompson et al., 2015: 2045). These patterns were interpreted as a response to the spill, with microbes being able to quickly proliferate and increase their litter decomposition rates in the absence of other macroinvertebrates crucial for this role in the river food web. The ability to change was crucial for the microbial communities impacted by the pesticide incident, but what can be learnt about adaptation from the anthropogenic devastation of the Kennet? What can this incident teach us about conscientious river ecopolitics? Aside from the commitment to avoid future spills, what modalities and forms can listening to the river take? The incident shows that microbial communities were able to grow and adapt, thus suggesting a case of turning a challenge into an opportunity. But what can the fate of the crustacean Gammarus pulex, who was decimated by the spill, tell us about the dynamics of dramatic ecosystem crisis and shifts? There are important lessons to learn, in terms of the complexity of adaptation, devastation and disrupted temporal trajectories that defy linear understandings of growth, development and collapse. Scientific accounts of complex entities like freshwater ecosystems assist in providing understandings of species interactions and the dynamics of diverse environments such as rivers. But this appears as only the beginning of a commitment. For the social sciences determined to move beyond the nature/culture separation and become sensitive to geosocial bodies of water and their communities, there is a need for attentive conscientiousness and the capacity to observe, listen to and inhale the tones, scents and articulations of microbial rivers. Only then it is possible to fully appreciate and recognise stories of both renewal and collapse and remember the communities foolishly decimated by anthropogenic interventions.

\section{Frozen States in Adverse Times}

To consider how ideas of flow and frozen states can assist in addressing disruptive events affecting individuals and communities, in this segment I divert through the field of body-oriented therapy. Somatic understandings of the ways in which traumatic events affect the human body offer ways to rethink challenges and responses to threats, as well as contribute to a recognition of the corporeal nature of adversities. Somatic Experiencing is a novel embodied approach to trauma healing created by the therapist Peter Levine. The effectiveness of this modality is based on the premise that when an organism encounters an overwhelming event, it may resort to a biological mechanism known as freezing. The freeze response can be 
seen as the 'last option' used when fight or flight are not viable (Levine, 1997: 99). For Levine, it is the contraction of the energy repressed in the freeze response that, if the organism survives the threat, constitutes trauma (Levine, 1997).

This image of frost in the therapeutic context illustrates how powerful watery metaphors such as freezing and flow pervade our language (Chen et al., 2013). Water is constantly moving and changing, it is reversible and mutable into different states from ice to steam (Strang, 2004). These oppositional states themselves, including frost, are infused with different meanings. Because of its changing and fluid qualities, Strang argues that water is the most suitable element to provide homologues and explain human experiences. Water metaphors such as freezing or floods of emotion describe emotional states and human experiences shared across cultures (Ibid). Metaphors of flow in the therapeutic context in particular show the interdependency of wellbeing and the ability to move through challenges, where immobility represents an impediment to growth.

For an individual stuck in the freeze response, this state entails a constant sense of overwhelm and terror that can only be overcome through a process of discharge and reintegration of the frozen energy. Levine advises that this is done in a controlled environment and in gradual fashion. This is because releasing the frozen energy all at once risks re-traumatising the individual (Levine, 1997). Through an effective interdisciplinary exercise, Levine borrows from chemistry the concept of titration as a way to safely reach a balance between activation and overwhelm (Levine, 2010). This is similar to how hydrochloric acid and lye are carefully and gradually mixed together in order to avoid an explosion. If mixed drop by drop, the combination of these elements results in the formation of water and salt. In the same way, through a process of titration, the slow and careful activation of the traumatic energy results in the eventual release, renegotiation and integration of the experience without awakening the incontrollable energy repressed at the moment the traumatic event occurred. Thus, it is in the overcoming of the frozen state that the individual can restore a state of flow and wellbeing.

This control of flow in the release of energy finds an analogy in Strang's description of "a "proper" order-boundaries and limits, a "correct balance" of flows' required to relate to social life, where 'a manageable "flow"' connects the unconscious to the analytical sphere and the individual to their social reality (2004: 68-69). The manipulation of flow has also been explored by Jamie Linton and Jessica Budds who note the political state-run control and regulation of water in place in structures like river dams (2013). Similarly, Franz Krause argues that along the Kemi River, in Lapland, 'many river dwellers experience dammed river stretches as the 
negation of flow' (2014: 90). In this context, hydropower and the control of water are perceived as a blockage to the naturally flowing river, thus complicating the notion of flow as a simply natural, passive and generalised flux (Krause, 2014). Jeanne Féaux de la Croix also considers how the 'stagnation' of water due to a hydroelectric dam in Kyrgyzstan affects the hesitance of the residents to engage meaningfully with it (2011: 498). Thus, flow entails diverse movements and blockages that manifest in multiple forms. In the particular context of the reinstatement of flow and wellbeing from the stuck energy of trauma, the form of control or moderation of flow, far from representing hierarchical management, acquires a horizontal and liberating element of renewal.

In an additional liquid metaphor, Levine and Phillips refer to 'flooding' as the state of 'being overwhelmed' and experiencing 'too much sensation', as opposed to a sense of dissociation from the body (2012: 60). Thus, while 'freezing' is a possible precursor of trauma, a downpour of sensation is as damaging and uncontrollable in its potential to swamp the individual. Watery metaphors of flow, flood and dynamic movement thus enable us to recognise that excessive sensations can be as overwhelming as immobility. While emotional floods can refer to overwhelming joy and floods can be considered acceptable when in the right place such as a wetland, they generally hold a negative connotation of imbalance and overwhelm that has the literal power to drown (Strang, 2004). If flooding sensations overtake the individual, floods also materially overtake entire communities. Somatic Experiencing has been used effectively to treat communities affected by environmental disasters such as the 2004 tsunami in Thailand (Leitch, 2007) and the 2005 hurricanes Katrina and Rita in Louisiana (Leitch et al., 2009). The release of frozen energy suppressed in response to these overwhelming water-related disasters was therefore beneficial for entire human communities.

Levine also talks about the significance of the 'felt sense', a concept proposed by philosopher Eugene Gendlin as a specific type of body awareness, a meaningful, physical, internal experience that can be identified and changed (Gendlin, 2003). The felt sense is much more multifaceted than language can express; it is a complicated concept to define because of its non-linearity but it can be considered as 'internal body sensations' that contain a 'fluidity necessary to transform the trauma' (Levine, 1997: 66-7). Thus, the felt sense is overall 'the medium through which we experience the totality of sensation' (Ibid: 68). As a bodily experience of life through the sense and internal awareness, the felt sense allows us to adapt to the circumstances (Levine, 1997). It is ultimately a 'radar' that enables us to understand the 'language of sensation', the nonverbal way our body communicates with us important clues about our experience of both the internal and the external environment (Levine \& 
Phillips, 2012: 6-7). In yet another water-related metaphor, Levine compares the concept to a moving stream that changes and adapts according to the environment, increasing in strength when its course is precipitous and becoming more peaceful and barely flowing when it reaches the plains (1997). The stream can also overflow following heavy rain. Therefore, it adapts itself to the environmental circumstances, in a characterisation that takes the metaphor back to the corporeal nature of water as matter (Chen et al., 2013). Levine's stream that adapts its course to shapes and turns, a liquid element that flows through the felt sense of the physical body, reminds of the depiction of water provided by Laozi in the ancient Chinese text Dao De Jing (or Tao Te Ching):

Nothing in the world is softer and weaker than water;

But, for attacking the hard and strong, there is nothing like it!

For nothing can take its place.

That the weak overcomes the strong, and the soft overcomes the hard, This is something known by all, but practised by none.

(Lao Tzu, 1961: 159)

For Laozi, softness and weakness constitute the strength of water and these water-like qualities apply to humans who, despite their awareness, fail to take notice. If water is soft, it is this trait that renders the element able to overcome forces that are inflexible and resistant. The softness, therefore, is a fluidity that adapts to any other element and circumstance, thus overcoming challenges. In the traumatic context explored above, it is through humans' soft quality, the nature of water and rivers, that it is possible to defeat the rigidity and stiffness of overwhelm. By practicing this knowing, humans can then experience, and reconnect to, the stream of the felt sense. Humans then emerge as made of the fluidity of water in the Daoist sense and they become who they are through their relationship with water. In their exploration of Daoist harmony, Yueh-Ting Lee, Honggang Yang and Min Wang argue that water emerges in Daoism as a powerful metaphor that also symbolises altruism, humility, flexibility, clarity and perseverance (Lee et al., 2009). Pollution and floods happen when the harmonious nature of water is out of balance, in the same way that all natural disasters can only erupt if there is lack of harmony (Ibid). When Lee, Yang and Wang ask, 'what can human beings learn from water?' (2009: 68), I extend their call to rivers. By considering the moving and changing nature of rivers and their communities it may be possible to counter a widespread, apocalyptic and destructive response to environmental degradation that entails defeatism and discouragement (Haraway, 2016). Thinking with rivers may assist in overcoming the problem of inaction and complacency resulting from the recognised failure to propose nationwide and structured plans to counter climate change and the still insufficient public engagement with the issue (Doan, 2014). 
Having considered the embodied immobility resulting from trauma, what happens when a river and its communities freeze in the face of challenges? An instance of this is found in the multiple frosts that hit the river Thames in the past centuries. On some of these occasions, the frost was so solid to allow the establishment of 'frost fairs' (Schneer, 2005). The frozen state of the Thames allowed then for a 'more democratic' relationship with the river where improvised tents would become stalls and shops from food to barbers, from prints to entertainment, offering new opportunities both in social and economic terms (Ibid: 69). It is then possible to consider that when a community freezes in trauma, this event can open spaces for renewal, following, rather than resisting, the challenge through the yielding quality of water that allows it to adapt to new environmental and social circumstances. When the river is frozen, there is still capacity for movement above its still course. The frost fairs emerge therefore as an analogy with the concept of 'post-traumatic growth', the opportunity 'to adapt to highly negative sets of circumstances that can engender high levels of psychological distress' (Tedeschi \& Calhoun, 2004: 2). Posttraumatic growth occurs after a traumatic episode and is not a mere coping mechanism, but entails a kind of transformation that exceeds the development in place before the event occurred (Tedeschi \& Calhoun, 2004). Far from constituting a hopeless circumstance that merely immobilises communities, the frozen river became then a chance to grow and develop beyond the pre-frost conditions. As many water metaphors hold a duality that portrays both overwhelming emotional experiences as well as joyful states of mind (Strang, 2004), frost conveys this duality particularly well. Frozen water then, and frozen energy in this specific context is not identified with stagnation and loss but acquires a meaning of growth and renewal.

And yet there are those who cannot flow, like the crustacean of the river Kennet. If there is a lesson to learn from the river spill, it is that resilience, a notion that entails self-governance, adaptation, empowerment and individual responsibility (Joseph \& McGregor, 2020), cannot be assumed or expected across intricately entangled eco-systems. In the current anthropogenic devastation that unequally affects different human and nonhuman communities, how can thinking with rivers assist those who cannot flow? How to listen to communities that become frozen and immobilised by unequally distributed environmental crisis? What kinds of hydro-logics can be proposed to become unstuck and move in flow? As environmental scientist Jules reminds me, communities form, communities change, communities die. But they also heal and recover. The geosocialities of microbial rivers then show the interconnection of microbes, humans and other species, where not only humans influence geological entities like rivers, but these very material elements 
continuously affect and inscribe humans and other organisms in changing interrelations. As watery organisms, it is in thinking with rivers and their multiple communities that we can re-establish a geosocial and ecopolitical connection that was always there but became forgotten. This hydrological move enables a recognition that raising the environmental issue of rivers may not be enough (Neimanis, 2017). The key is to challenge the human exploitation of watercourses as mere resources, recognising the human and nonhuman bodies inhabiting them, thus going beyond the humanism of dualisms (Ibid). To conceive of rivers in their geosocial and microbial elements allows for a decentring of the human from its primary position within the environment. It is then possible to recognise the human as part of the river community rather than its owner. Microbial rivers, with their many visible and invisible life forms, is then a call for novel ways to relate to nonhuman entities for their intrinsic rather than instrumental value. In considering flow as a necessary movement in human and nonhuman wellbeing, against the stagnation of stuck traumatic energy as well as turbid polluted water, it is possible to reconnect with 'others' -water, microbes, crustaceans -in more authentic and respectful ways. This shift also involves the recognition of the agency of rivers and their communities, as well as developing an awareness of humans' geosocial belonging to these ecosystems. It is this acknowledgement of our water-like quality of softness, a weakness that overcomes the strong, that allows us, after a challenge, to flow again like a stream. Thinking with rivers can then entail a repositioning of the human as part of situated water communities alongside other flowing organisms.

\section{Conclusion}

This article has traced a geosocial and interdisciplinary argument for the interconnectedness of rivers, microbes and humans in their fluid and soft qualities. Microbial rivers emerge in microbiology as complicated entities to delineate because of their diversity and constant movement. With their fluctuating components and inhabitants, microbial rivers affect sociality in multiple modalities and are in turn influenced by complex dynamics and elements. Flow carries microbes, soils, pollutants in its fluidity where communities form and respond to the challenge of immobility that prevents progress in the felt sense of life. Once the moving quality of rivers in the face of devastation is reinstated, human and nonhuman communities can undergo renewal and thrive. As organisms made of water, minerals and microbes, if humans become conscious of the geosocial entanglement with other lives, this realisation can entail a responsible awareness of river communities in their diverse sensitivities to anthropogenic devastation. It is then possible to recognise that growth and opportunity do not spring from individual resilience, but arise from harmony in the complex and intersected river flow. 


\section{Acknowledgements}

I would like to thank the scientist featured in this article for introducing me to river microbial communities. I also thank Guilherme Sampaio at Exchanges and two anonymous reviewers for their valuable comments and guidance.

Serena Zanzu is a research fellow at Warwick Business School, working on an ESRC/NPIF Postdoctoral Innovation Project. Her current research explores the complex relationship between social scientists and businesses in the context of food sustainability. She holds a PhD in Sociology from the University of Warwick. Her doctoral thesis examined the soil microbiome as a form of knowledge constituted across interconnected fields of expertise.

\section{References}

Chen, C., MacLeod, J. and Neimanis, A. (2013). Introduction: Toward a Hydrological Turn? In: Chen, C., MacLeod, J. and Neimanis, A., Thinking with Water, Montreal \& Kingston: McGill-Queen's University Press.

Clark, D. R., Ferguson, R. M. W., Harris, D. N., Nicholass, K. J. M., Prentice, H. J., Randall, K. C., Randell, L., Warren, S. L. and Dumbrell, A. J. (2018). Streams of Data from Drops of Water: 21st Century Molecular Microbial Ecology, WIREs Water, 5 (4) e1280.

Doan, M. D. (2014). Climate Change and Complacency. Hypatia, 29 (3), pp. 634650 .

Féaux de la Croix, J. (2011). Moving metaphors we live by: water and flow in the social sciences and around hydroelectric dams in Kyrgyzstan. Central Asian Survey, 30 (3-4), pp. 487-502.

Gendlin, E. T. (2003). Focusing, London: Rider.

Haraway, D. (2016). Staying with the Trouble: Making Kin in the Chthulucene. Durham and London: Duke University Press.

Harding, S. and Margulis, L. (2009). Water Gaia: 3.5 Thousand Million Years of Wetness on Planet Earth. In: Crist, E. and Rinker, H. B. (eds.). Gaia in Turmoil: Climate Change, Biodepletion, and Earth Ethics in an Age of Crisis. Cambridge, MA: MIT Press.

Hastrup, K. (2013). Water and the configuration of social worlds: An anthropological perspective. Journal of Water Resource and Protection, 5, pp. $59-66$. 
Hawke, S. (2012). Water Literacy: An 'Other wise', Active and Cross-cultural Approach to Pedagogy, Sustainability and Human Rights. Continuum, 26 (2), pp. 235-247.

Hawke, S. and Pálsson, G. (2017). Water Futures, Biosociality, and Other-Wise Agency: An Exploratory Essay. Anuac, 6 (1), pp. 233-252.

Helmreich, S. (2009). Alien ocean: anthropological voyages in microbial seas. Berkeley: University of California Press.

Hird, M. (2009). The Origins of sociable life: Evolution after science studies. Basingstoke: Palgrave Macmillan.

Joseph, J. and McGregor, J. A. (2020). Wellbeing, Resilience and Sustainability: The New Trinity of Governance. Basingstoke: Palgrave Macmillan.

Krause, F. (2014). Reclaiming flow for a lively anthropology. Suomen Antropologi: Journal of the Finnish Anthropological Society, 39 (2), pp. 89-92.

Krause, F. and Strang, V. (2016). Thinking relationships through water. Society and natural resources, 29 (6), pp. 633-638.

Lakoff, G. and Johnson, M. (1980). Metaphors we live by. Chicago: University of Chicago Press.

Lao Tzu (1961). Tao Teh Ching (Translated by John Ching Hsiung Wu). New York: Barnes \& Nobles.

Lee, Y., Yang, H. and Wang, M. (2009). Daoist Harmony as a Chinese Philosophy and Psychology. Peace and Conflict Studies, 16 (1), pp. 68-81.

Leitch, M. L. (2007). Somatic Experiencing Treatment with Tsunami Survivors in Thailand: Broadening the Scope of Early Intervention. Traumatology, 13 (3), pp. 11-20.

Leitch, M. L., Vanslyke, J. and Allen, M. (2009). Somatic Experiencing Treatment with Social Service Workers Following Hurricanes Katrina and Rita. Social Work, 54 (1): 9-18.

Levine, P. A. (1997). Waking the Tiger: Healing Trauma: The Innate Capacity to Transform Overwhelming Experiences. Berkeley, CA: North Atlantic Books.

Levine, P. A. (2010). In an Unspoken Voice: How the Body Releases Trauma and Restores Goodness. Berkeley, CA: North Atlantic Books.

Levine, P. A. and Phillips, M. (2012). Freedom from Pain: Discover your Body's Power to Overcome Physical Pain. Boulder, CO: Sounds True.

Linton, J. and Budds, J. (2013). The hydrosocial cycle: Defining and mobilizing a relational-dialectical approach to water. Geoforum, 57, pp. 170-180.

Lowe, C. (2017). Viral ethnography: Metaphors for writing life. In: Troubling Species: Care and Belonging in a Relational World, by The Multispecies Editing Collective, RCC Perspectives: Transformations in Environment and Society, 1, pp. 91-96. 
Mari, L., Casagrandi, R., Bertuzzo, E., Rinaldo, A and Gatto, M. (2014). Metapopulation Persistence and Species Spread in River Networks. Ecology Letters, 17 (4), pp. 426-434

Neimanis, A. (2013). Morning sickness and gut sociality. Towards a posthumanist feminist phenomenology. Janus Head, 13 (1), pp. 214-240.

Neimanis, A. (2017). Bodies of water: posthuman feminist phenomenology, London: Bloomsbury Academic.

Orlove, B. and Caton, S. C. (2010). Water sustainability: Anthropological approaches and prospects. Annual Review of Anthropology, 9, pp. 401-415.

Pálsson, G. and Swanson, H. A. (2016). Down to Earth: Geosocialities and Geopolitics. Environmental Humanities, 8 (2), pp. 149-171.

Paxson, H. and Helmreich, S. (2014). The perils and promises of microbial abundance: Novel natures and model ecosystems, from artisanal cheese to alien seas. Social Studies of Science, 44 (2), pp. 165-193.

Rockefeller, S. A. (2011). Flow. Current Anthropology, 52 (4), pp. 557-578.

Sarukkai, S. (2009). Science and the Ethics of Curiosity. Current Science, 97 (6), pp. 756-767.

Savio, D., Sinclair, L., ljaz, U. Z., Parajka, J., Reischer, G. H., Stadler, P., Blaschke, A. P., Blöschl, G., Mach, R. L., Kirschner, A. K. T., Farnleitner, A. H. and Eiler, A. (2015). Bacterial Diversity along a $2600 \mathrm{~km}$ River Continuum. Environmental Microbiology. 17 (12), pp. 4994-5007.

Schneer, J. (2005). The Thames. New Haven \& London: Yale University Press.

Schrader, A. (2017). Microbial suicide: Towards a less anthropocentric ontology of life and death. Body \& society. 23 (3), pp. 48-74.

Schrader, A. (2020). Marine microbiopolitics: Haunted microbes before the Law. In: Braverman, I. and Johnson, E. R. (eds.). Blue legalities: The life and laws of the sea. Durham and London: Duke University Press.

Strang, V. (2004). The meaning of water. Oxford, New York: Berg.

Tedeschi, R. G. and Calhoun, L. G. (2004). Target article: Posttraumatic growth: Conceptual foundations and empirical evidence. Psychological Inquiry, 15, pp. 1-18.

Thompson, M. S. A., Bankier, C., Bell, T., Dumbrell, A. J., Gray, C., Ledger, M. E., Lehmann, K., McKew, B. A., Sayer, C. D., Shelley, F., Trimmer, M., Warren, S. L. and Woodward, G. (2015). Gene-to-ecosystem Impacts of a Catastrophic Pesticide Spill: Testing a Multilevel Bioassessment Approach in a River Ecosystem. Freshwater Biology, 61 (12), pp. 2037-2050.

Vaz-Moreira, I., Nunes, O. C. and Manaia, C. M. (2014). Bacterial Diversity and Antibiotic Resistance in Water Habitats: Searching the Links with the Human Microbiome. FEMS Microbiology Reviews, 38 (4), pp. 761-778. 
Yaka, Ö. (2020). Justice as relationality: Socio-ecological justice in the context of anti-hydropower movements in Turkey. DIE ERDE - Journal of the Geographical Society of Berlin, 151 (2-3), pp. 167-180.

\section{To cite this article:}

Zanzu, S., 2021. Geosocialities, Flow and Renewal in Microbial Rivers. Exchanges: The Interdisciplinary Research Journal, 9(1), 24-44. Available at: https://doi.org/10.31273/eirj.v9i1.740. 